\title{
Prophylactic positive end-expiratory pressure and postintubation hemodynamics: An interventional, randomized study
}

\author{
Olivier Lesur MD MSc PhD ${ }^{1,2,3}$, Marie-Anaïs Remillard MD², Catherine St-Pierre MD ${ }^{1,2}$, Simon Falardeau MD²
}

O Lesur, M-A Remillard, C St-Pierre, S Falardeau. Prophylactic positive end-expiratory pressure and postintubation hemodynamics: An interventional, randomized study. Can Respir J 2010;17(3):e45-e50.

OBJECTIVE: To investigate the hemodynamic and outcome effects of implementing prophylactic positive end-expiratory pressure (PEEP) versus zero end-expiratory pressure (ZEEP) in patients during the postintubation period in the emergency setting.

METHODS: The present study was a prospective, single-centre, interventional, single-blinded randomized trial performed in a 16-bed medical intensive care unit. The study cohort consisted of consecutive patients who urgently required intubation. During the postintubation period, patients received either $5 \mathrm{cmH}_{2} \mathrm{O}$ PEEP or ZEEP. The primary aim was to assess the variation in mean arterial pressure (MAP) from baseline up to 90 min postintubation. The secondary aim was to determine the mean duration of intubation, level of MAP support after intubation and 28-day mortality.

RESULTS: Seventy-five consecutive patients with similar mean $( \pm$ SD) baseline characteristics and preintubation MAP $(76 \pm 18 \mathrm{mmHg}$ in the ZEEP group and $78.5 \pm 23 \mathrm{mmHg}$ in the PEEP group, $\mathrm{P}=$ Not significant [NS]) were studied. The final analysis was performed in 33 patients in the ZEEP group and 30 patients in the PEEP group. Regarding outcome measures following intubation, delta MAP (ie, the difference between the lowest MAP values from baseline) was not differentially affected in either group $(\mathrm{P}=\mathrm{NS})$; the mean durations of intubation were similar (ZEEP 9.2 \pm 8.5 days versus PEEP 9.2 \pm 8.8 days, $\mathrm{P}=\mathrm{NS}$ ); 28-day mortality was not discriminative (ZEEP 14 of 33, PEEP nine of 30; $\mathrm{P}=\mathrm{NS}$ ); and levels of MAP support after intubation were comparable between the two groups. .

CONCLUSION: In the present trial, there was no evidence that implementing a prophylactic PEEP of $5 \mathrm{cmH}_{2} \mathrm{O}$ adversely affects short-term hemodynamics or outcome in medical intensive care patients during the postintubation period.

\section{L'hémodynamique d'une pression expiratoire positive prophylactique et après l'intubation : Une étude aléatoire interventionnelle}

\begin{abstract}
OBJECTIF : Explorer l'hémodynamique et les mesures d'issue d'une pression expiratoire positive (PEP) par rapport à aucune pression expiratoire (APE) chez les patients après la période d'intubation à l'urgence.

MÉTHODOLOGIE : La présente étude était un essai prospectif aléatoire interventionnel unicentrique à simple insu mené dans une unité de soins intensifs de 16 lits. La cohorte à l'étude se composait de patients consécutifs qui avaient besoin d'être intubés d'urgence. Après l'intubation, les patients ont reçu soit une PEP de $5 \mathrm{~cm}$ d'eau, soit APE. L'objectif primaire consistait à évaluer la variation de la pression artérielle moyenne (PAM) entre le point de départ et 90 minutes suivant l'intubation. L'objectif secondaire visait à déterminer la durée moyenne de l'intubation, le taux de soutien de la PAM après l'intubation et la mortalité au bout de 28 jours.

RÉSULTATS : Les chercheurs ont étudié 75 patients consécutifs ayant des caractéristiques de départ moyennes ( \pm ÉT) et une PAM avant l'intubation $(76 \pm 18 \mathrm{mmHg}$ dans le groupe n'ayant APE et $78,5 \pm 23 \mathrm{mmHg}$ dans celui ayant une $\mathrm{PEP}, \mathrm{P}=$ non significatif [n.s.]) similaires. Ils ont effectué l'analyse finale chez 33 patients du groupe n'ayant APE et chez 30 patients ayant une PEP. Pour ce qui est des mesures d'issue après l'intubation, la valeur différentielle de la PAM delta (c'est-à-dire la différence entre les valeurs de PAM minimales par rapport au point de départ) n'était pas touchée dans l'un ou l'autre groupe $(\mathrm{P}=$ n.s. $)$, la durée moyenne de l'intubation était similaire (APE $9,2 \pm 8,5$ jours par rapport à $P E P$ 9,2 $\pm 8,8$ jours, $P=$ n.s.), la mortalité au bout de 28 jours n'était pas discriminante (APE 14 sur 33, PEP neuf sur $30 ; \mathrm{P}=$ n.s.) et les taux de soutien de la PAM après l'intubation étaient comparables entre les deux groupes.

CONCLUSION : Dans la présente étude, aucunes données n'indiquaient que l'adoption d'une PEP prophylactique de $5 \mathrm{~cm}$ d'eau nuit à l'hémodynamique ou à l'issue à court terme chez les patients à l'unité de soins intensifs après l'intubation.
\end{abstract}

Key Words: Hemodynamics; Intubation; Positive end-expiratory pressure

Tntubation with subsequent positive pressure ventilation (PPV) during acute respiratory failure is an invasive technique and, therefore, has the potential for many associated complications or side effects (1). Fortunately, the benefits generally outweigh the risks. Several observational studies (2-4) have described the rate and nature of immediate complications following urgent intubation (outside the operating room), including hemodynamics, that may be further affected by PPV initiation. Indeed, PPV alters the normal physiological pressures in the chest; consequently, both heart and thoracic vessel functions are affected, depending on the amount of positive pressure applied and the pathophysiology of the underlying lungs $(1,5)$.

It has been well established for several decades that decreased cardiac output is one of the primary consequences of PPV, and is associated with the inversion of the

\footnotetext{
${ }^{1}$ Soins Intensifs Médicaux, Centre Hospitalier Universitaire de Sherbrooke; ${ }^{2}$ Département de Médecine, Faculté de Médecine et des Sciences de la Santé; ${ }^{3}$ Groupe de Recherche en Physiopathologie Respiratoire, Centre de Recherche Clinique, Centre Hospitalier Universitaire de Sherbrooke, Sherbrooke, Quebec

Correspondence: Dr Olivier Lesur, Groupe de Recherche en Physiopathologie Respiratoire, Centre de Recherche Clinique, Unité des Soins Intensifs Médicaux, Centre Hospitalier Universitaire de Sherbrooke, 3001, 12 me Avenue Nord, Sherbrooke, Quebec J1H 5N4.

Telephone 819-346-1110,fax 819-564-5377,e-mail olivier.lesur@usherbrooke.ca
} 
intrathoracic pressure gradient during inspiration, with increased central venous pressure (CVP) and reduced return blood flow to the heart. Hence, the higher the mean airway pressure, the greater the effects, although the impact of PPV on cardiac output is minimal with up to $20 \mathrm{cmH}_{2} \mathrm{O}(1,5-7)$.

The goals of applying positive end-expiratory pressure (PEEP) in addition to PPV are to increase functional residual capacity and alveolar recruitment, redistribute extravascular lung water and improve ventilation-perfusion matching $(1,5,6)$. The effects of PEEP on heart function are greater than with PPV alone. Potential effects of PEEP on left ventricular dysfunction include the following: reduced venous return, with increased airway and intrathoracic pressures; increased functional residual capacity from PEEP, with increased pulmonary vascular resistance and afterload to the right heart; left shift of the interventricular septum affecting left ventricular volume; and mechanical compression of the heart and aorta, with positive pleural pressure (6-10).

In fact, prophylactic PEEP initiation is a controversial, nonevidence-based procedure that is often empirically applied (11). Although PEEP is not recognized to induce a reduction in cardiac output when not greater than $15 \mathrm{cmH}_{2} \mathrm{O}$, some intensive care unit (ICU) physicians are apprehensive about initiating prophylactic PEEP of $5 \mathrm{cmH}_{2} \mathrm{O}$ to $10 \mathrm{cmH}_{2} \mathrm{O}$, especially when circulation volume is uncertain $(5,12-14)$. On the other hand, initiating an 'observational period' without PEEP following endotracheal tube (ETT) connection to the ventilator is a procedure that has never been assessed with regard to its impact on short-term hemodynamics and long-term outcome measures.

The aim of the current trial was to demonstrate that initiating $5 \mathrm{cmH}_{2} \mathrm{O}$ PEEP versus zero end-expiratory end pressure (ZEEP) in the 90 min postintubation period does not significantly affect the hemodynamic status of medical ICU patients, nor does it influence overall outcome (ie, duration of mechanical ventilation $[\mathrm{MV}]$ or 28-day mortality).

\section{METHODS}

The variation in mean arterial pressure (MAP) from baseline up to 90 min postintubation (ie, delta MAP), with and without applied PEEP (independent variable), was the primary outcome measure. Secondary outcome measures addressed mean duration of intubation, level of MAP support after intubation and 28-day mortality.

\section{Patients}

The present study was a prospective, single-centre, interventional, single-blinded, randomized trial involving consecutive patients with a clinical indication for endotracheal intubation. The trial was performed at the Centre Hospitalier Universitaire de Sherbrooke - Hôpital Fleurimont (Sherbrooke, Quebec), which includes 16 medical ICU beds. The study protocol was approved by local institutional ethics committees and informed consent was obtained from each patient or the next of kin.

All patients requiring endotracheal intubation for acute respiratory failure after admission to the medical ICU were eligible. Exclusion criteria were as follows: cardiac arrest or malignant arrhythmia, inability to monitor MAP, patients 17 years of age or younger, MV (including noninvasive ventilation) in the $2 \mathrm{~h}$ preceding intubation and 'do-not-resuscitate' patients.

\section{Protocolized and nonprotocolized procedures}

A computer-generated block randomization list was prepared by the principal investigator (Olivier Lesur). Randomization was concealed using numbered, sealed, opaque envelopes. On assessment of the patient's eligibility, the randomization process was initiated by the opening of the first numbered envelope by the 'on ward' respiratory therapist. The ICU physician on duty was blinded to this procedure; the respiratory therapist adjusted the MV parameters (according to the physician's recommendations) with ZEEP or PEEP (according to the study's allocation), masking visual identification of allocation for the following $90 \mathrm{~min}$. The ICU physician could halt the blinding at any moment, whenever he or she was not comfortable with the protocol.

MAP was monitored every $2 \mathrm{~min}$ and recorded at $5 \mathrm{~min}$ intervals from the initiation of ventilator connection up to $90 \mathrm{~min}$ thereafter. MAP data were directly recorded at bedside using a monitor (Hewlett-Packard, USA) and were collected from the arterial pressure line or, occasionally (less than $5 \%$ ), by noninvasive pressure measurement. The lowest MAP values for each individual and period were selected to be representative for delta calculation and mean measurements. The average time lapse between ETT introduction and ventilator connection was approximately $5 \mathrm{~min}$ and was defined as the time needed by the respiratory therapist to secure the ETT. Other data were obtained directly from the hospital's computerized data system containing medical files and laboratory documents.

Depending on equipment availability, baseline measurements of central venous pressure (CVP) were recorded. Neither anesthesia for ETT placement nor the levels and types of intervention for maintaining MAP after intubation were codified; all were left to the discretion of the on-duty physician.

\section{Trial definitions}

MAP was monitored every 2 min. Hypotension was considered clinically significant when MAP dropped below $65 \mathrm{mmHg}$ for at least $10 \mathrm{~min}$ or below $60 \mathrm{mmHg}$ for at least $5 \mathrm{~min}$, or treatment/intervention was mandatory (fluid or drug administration, or a greater than $50 \%$ increase in ongoing administered vasopressor). Levels of intervention to rescue hypotensive events were scaled as follows: $0=$ no intervention; $1=$ Trendelenburg position (or equivalent) or a saline flush $(500 \mathrm{~mL}$ or less), or a $10 \mu \mathrm{g}$ phenylephrine intravenous bolus; 2 = greater than a $500 \mathrm{~mL}$ saline infusion or more than one $10 \mu \mathrm{g}$ phenylephrine intravenous bolus (or initiation of phenylephrine perfusion); 3 = other vasopressor(s) added to intervention level 2 (eg, dopamine, noradrenaline); and $4=$ more than one of the above interventions. This scale of interventions was established after a pilot validation study in our medical ICU that investigated current practices for hypotension management following intubation.

\section{Statistical analysis}

The primary end point was the mean drop in MAP with intubation and MV, as assessed by the 'delta' MAP from baseline to $90 \mathrm{~min}$ following ventilator connection (at $15 \mathrm{~min}$ intervals for the first $30 \mathrm{~min}$, and at $30 \mathrm{~min}$ intervals up to $90 \mathrm{~min}$ total thereafter). It was calculated that at least 30 patients would be required in each group to enable the detection of a $15 \%$ difference in MAP, assuming an alpha risk of 0.05 and a beta risk of 


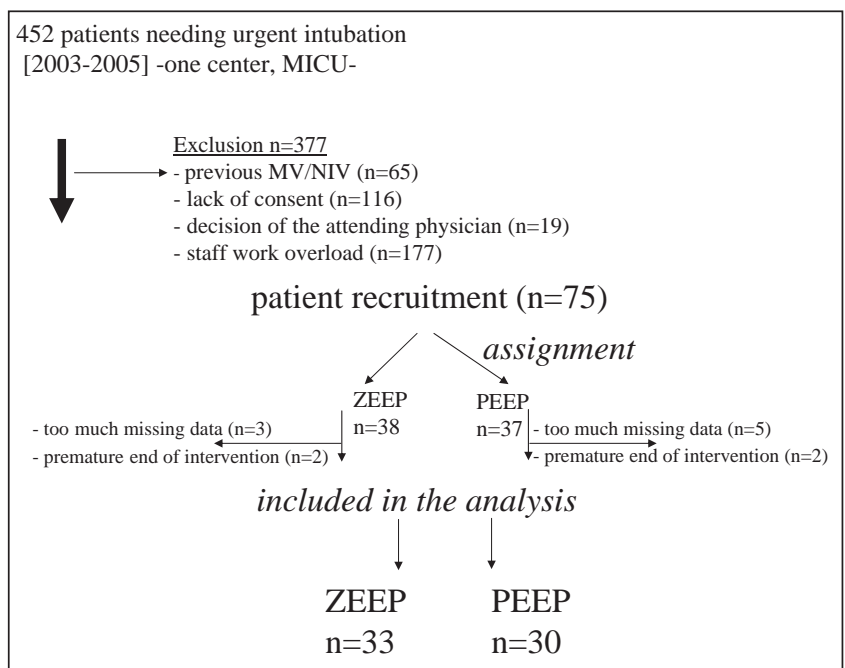

Figure 1) Flow of patients through each stage of the study inclusion procedure. From 2003 to 2005, 452 patients needed intubation for acute respiratory failure, of which 377 were not included (exclusion rate $=83 \%)$. Of the 75 patients recruited, 12 were not included in the final analysis, with the remaining patients assigned to the final groups: Zero end-expiratory pressure (ZEEP) $(n=33)$ and positive end-expiratory pressure (PEEP) $(n=30)$. MICU Medical intensive care unit; MV Mechanical ventilation; NIV Noninvasive ventilation

0.8 ( $80 \%$ power). Secondary outcome measures were the number of days of MV and 28-day mortality. Data were expressed as mean $\pm \mathrm{SD}$. Normality for each variable was assessed using the Shapiro-Wilks test. Baseline characteristics were compared using the unpaired Student's $t$ test for quantitative variables and the Fisher's exact test for categorical variables. Nonparametric variables were analyzed using the Mann-Whitney $U$ test for comparisons between groups and with the Kruskal-Wallis test for comparison within groups. A two-sided Fisher's exact test was used for subgroup analysis in contingency tables. All statistics were performed using InStat 3.0 (GraphPad Software Inc, USA), and comparisons with $\mathrm{P}<0.05$ were considered to be statistically significant.

\section{RESULTS}

Although the ratio of screened to included patients was relatively low (Figure 1), the randomization process was harmoniously performed, as shown in Table 1 . The general characteristics of both intention-to-treat study groups were very similar and representative of a typical medical ICU admission profile. Sepsis was a leading cause of intubation in both ZEEP and PEEP groups (18 of 33 and 20 of 30, respectively), and a direct cause of respiratory failure (15 of 33 and 16 of 30 , respectively) (Table 2). Both groups exhibited similar occurrence of hypotension during and after intubation procedures (ZEEP 18 of 18, PEEP 17 of $20 ; \mathrm{RR}=0.49,95 \%$ CI 0.35 to $0.68 ; \mathrm{P}=0.23$ ). The Acute Physiology and Chronic Health Evaluation scores predicted a mortality rate of $30 \%$ to $35 \%$.

Table 2 summarizes the reasons for intubation, of which more than two-thirds were associated with cardiorespiratory failure and highlighted by the fact that more than one-third of patients were already exhibiting significant systolic dysfunction. Initial selection of MV (PPV) modes and parameters were
TABLE 1

General characteristics of the study population

\begin{tabular}{|c|c|c|c|}
\hline & $\begin{array}{c}\text { ZEEP }=0 \mathrm{cmH}_{2} \mathrm{O} \\
(\mathrm{n}=33)\end{array}$ & $\begin{array}{c}\text { PEEP }=5 \mathrm{cmH}_{2} \mathrm{O} \\
(n=30)\end{array}$ & $\mathbf{P}$ \\
\hline Age, years (mean \pm SD) & $64 \pm 18$ & $65 \pm 14$ & 0.74 \\
\hline Male sex, n & 21 & 17 & 0.63 \\
\hline APACHE II score, mean \pm SD & $19.5 \pm 7.6$ & $18.5 \pm 5.5$ & 0.78 \\
\hline \multicolumn{4}{|l|}{ Chronic health/diseases, $\mathrm{n}$} \\
\hline Heart & 18 & 16 & 0.94 \\
\hline Dyslipidemia & 8 & 12 & 0.27 \\
\hline Arterial hypertension & 12 & 12 & 0.81 \\
\hline Atrial fibrillation & 5 & 6 & 0.74 \\
\hline COPD/asthma & 10 & 8 & 0.80 \\
\hline Neoplasia & 9 & 8 & 0.97 \\
\hline Hematological & 3 & 7 & 0.31 \\
\hline Kidney & 5 & 4 & 0.90 \\
\hline Obesity (BMI >40 kg/m²) & 1 & 3 & 0.68 \\
\hline Neurological & 4 & 2 & 0.70 \\
\hline Gastrointestinal & 7 & 5 & 0.75 \\
\hline Diabetes mellitus & 4 & 10 & 0.13 \\
\hline Endocrinological (others) & 4 & 2 & 0.70 \\
\hline Alcohol and toxic/drug & 2 & 3 & 0.78 \\
\hline
\end{tabular}

abuse

APACHE Acute Physiology and Chronic Health Evaluation; BMI Body mass index; COPD Chronic obstructive pulmonary disease; PEEP Positive endexpiratory pressure; ZEEP Zero end-expiratory pressure

TABLE 2

Causes of intubation, ventilatory parameters and gas-exchange abnormalities

\begin{tabular}{|c|c|c|c|}
\hline & $\begin{array}{c}\text { ZEEP }=0 \mathrm{cmH}_{2} \mathrm{O} \\
(\mathrm{n}=33)\end{array}$ & $\begin{array}{c}\text { PEEP }=5 \mathrm{cmH}_{2} \mathrm{O} \\
(\mathrm{n}=30)\end{array}$ & $\mathbf{P}$ \\
\hline \multicolumn{4}{|l|}{ Reasons for intubation, $\mathrm{n}$} \\
\hline Respiratory & 15 & 16 & 0.35 \\
\hline Cardiovascular & 2 & 3 & 0.78 \\
\hline Mixed cardiorespiratory & 5 & 4 & 0.40 \\
\hline Neurological & 8 & 5 & 0.60 \\
\hline Miscellaneous & 3 & 2 & 1.00 \\
\hline Initial ventilatory parameters & VC $(n=23) / P C(n=10)$ & $\operatorname{VC}(n=21) / P C(n=9)$ & \\
\hline $\mathrm{Vt}, \mathrm{mL} / \mathrm{kg}$ EBW & $7.3(6.4-8.4)$ & $8.3(6.1-9.2)$ & 0.99 \\
\hline $\mathrm{mPaw}, \mathrm{cmH}_{2} \mathrm{O}$ & $10(6.5-13)$ & $10(9-12)$ & 0.59 \\
\hline $\mathrm{RR}$, breaths/min & $12(11-17)$ & $12(12-15)$ & 0.89 \\
\hline \multicolumn{4}{|c|}{ Gas-exchange parameters before intubation } \\
\hline $\mathrm{PaO}_{2} / \mathrm{FiO}_{2}$ & $176(74-414)$ & $250(76-422)$ & 0.79 \\
\hline $\mathrm{pH}$ & $7.37(7.3-7.45)$ & $7.41(7.3-7.44)$ & 0.77 \\
\hline \multicolumn{4}{|c|}{ Gas-exchange parameters 90 min after MV initiation* } \\
\hline $\mathrm{PaO}_{2} / \mathrm{FiO}_{2}$ & $222.5(187-274)$ & 269 (218-392) & 0.10 \\
\hline $\mathrm{pH}$ & 7.39 (7.34-7.47) & $7.37(7.3-7.43)$ & 0.37 \\
\hline
\end{tabular}

Data presented as median (interquartile range) unless indicated otherwise. ${ }^{*}$ Four and three arterial gas measurements were missing in the zero endexpiratory pressure (ZEEP) and positive end-expiratory pressure (PEEP) groups, respectively. EBW Effective body weight; $\mathrm{FiO}_{2}$ Fraction of inspired oxygen; mPaw Mean airway pressure; MV Mechanical ventilation; $\mathrm{PaO}_{2}$ Partial pressure of oxygen; PC Pressure-controlled MV; RR Respiratory rate; VC Volume-controlled MV, Vt Tidal volume

essentially similar (Table 2). Gas exchange parameters were comparable in both groups either before or $90 \mathrm{~min}$ after intubation (Table 2), as well as $24 \mathrm{~h}$ after PPV initiation (data not shown). Baseline CVP was recoverable in almost $50 \%$ of the cohort and, was in large part, similar in both groups (ZEEP $10.8 \pm 2.9 \mathrm{mmHg}$ versus PEEP $12.5 \pm 1.5 \mathrm{mmHg}, \mathrm{P}$ not 


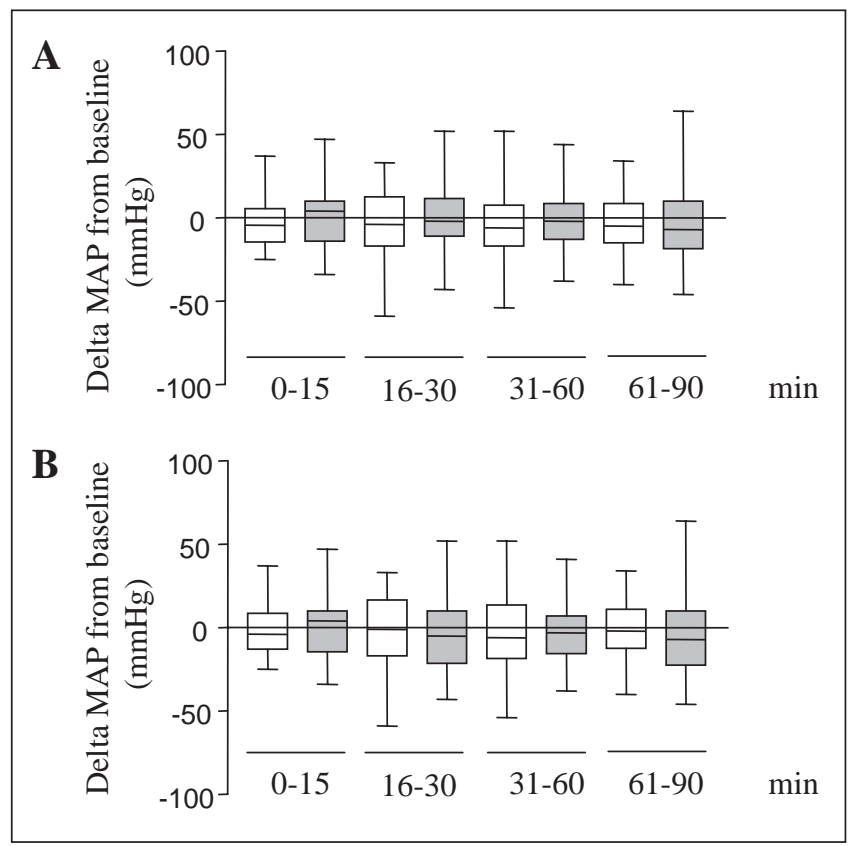

Figure 2) Serial changes of mean arterial pressure (MAP) during the $90 \mathrm{~min}$ time period. Values were pooled into four periods of $15 \mathrm{~min}$ for the first two, and $30 \mathrm{~min}$ for the final two periods. Data have been expressed as the difference (delta $\mathrm{mmHg}$ ) of MAP from baseline for each individual. White boxes: zero end-expiratory pressure (ZEEP) patients; grey boxes: positive end-expiratory pressure (PEEP) patients; horizontal line: median; box: interquarttile range; error bars: 10th to 90th percentile range. A All patients included. B Patients without pre-existing hypotension (ZEEP [n=27]; PEEP [n=21])

significant [NS]), as well as in subsets of hypotensive patients (ZEEP 11.3 $\pm 1.4 \mathrm{mmHg}$ versus PEEP $13.8 \pm 1.8 \mathrm{mmHg}, \mathrm{P}=\mathrm{NS}$ ). Baseline (before intubation) median MAP values were $70 \mathrm{mmHg}$ (interquartile range $62.5 \mathrm{mmHg}$ to $88.5 \mathrm{mmHg}$ ) and $77 \mathrm{mmHg}$ (interquartile range $59 \mathrm{mmHg}$ to $94 \mathrm{mmHg}$ ) in ZEEP and PEEP groups, respectively ( $\mathrm{P}=\mathrm{NS}$ ). Hypotension subsequent to ETT placement, as defined in the present trial, was a frequent event ( $50 \%$ of patients). However, pre-existing cardiac dysfunction, regardless of applied PEEP, did not increase the occurrence of hypotension ( $\mathrm{RR}=0.7576,95 \% \mathrm{CI} 0.3479$ to $1.650, \mathrm{P}=0.716$ ). Comparisons of MAP variations during the 90 min time scale did not allow group discrimination with regard to drop-off (Figure 2A), and was readily maintained even when excluding patients that were hypotensive before ETT placement and PPV initiation (Figure 2B)

Interventions for hypotension (as defined in the Methods section) were mandatory in 16 patients in both groups $(48.5 \%$ ZEEP versus $53.3 \%$ PEEP, $\mathrm{P}=\mathrm{NS}$ ). More specifically, hypotension was pre-existent to MV initiation in less than one-third of patients in both groups $(\mathrm{P}=\mathrm{NS})$ (Table 3$)$. Hypotension was paradoxically more frequent in patients with mild or no myocardial dysfunction, and levels of intervention were similar in both groups (ZEEP/PEEP): level $1(n=1) /(n=4)$, level $2:(n=4) /$ $(n=5)$, level $3(n=8) /(n=6)$ and level $4:(n=3) /(n=1)(P=N S)$.

Documented 28-day patient mortality was slightly above that predicted by the Acute Physiology and Chronic Health Evaluation II score. However, while slightly higher in the ZEEP
TABLE 3

Cardiovascular status before and after intubation

\begin{tabular}{|c|c|c|c|}
\hline & $\begin{array}{c}\text { ZEEP }=0 \mathrm{cmH}_{2} \mathrm{O} \\
(n=33)\end{array}$ & $\begin{array}{c}\text { PEEP }=5 \mathrm{cmH}_{2} \mathrm{O} \\
(n=30)\end{array}$ & $\mathbf{P}$ \\
\hline LVEF below $40 \% *$ & 10/27 (37.0) & $11 / 24(45.8)$ & 0.59 \\
\hline Hypotension occurrence & 16/33 (48.5) & $16 / 30(53.3)$ & 0.74 \\
\hline $\begin{array}{l}\text { Hypotension occurrence } \\
\text { with LVEF <40\% }\end{array}$ & $5 / 16(31.3)$ & $7 / 16(43.8)$ & 0.55 \\
\hline Pre-exisitng hypotension ${ }^{\dagger}$ & 6/33 (18.2) & 9/30 (30.0) & 0.41 \\
\hline
\end{tabular}

Data presented as $n / n$ (\%) unless indicated otherwise. *Assessed by echocardiography or ventriculography less than one year before; ${ }^{\dagger}$ Patient hypotension before intubation and mechanical ventilation. LVEF Left ventricular ejection fraction; PEEP Positive end-expiratory pressure; ZEEP Zero endexpiratory pressure

TABLE 4

Secondary end points and outcome measures

\begin{tabular}{|c|c|c|c|}
\hline & $\begin{array}{c}\text { ZEEP }=0 \mathrm{cmH}_{2} \mathrm{O} \\
(n=33)\end{array}$ & $\begin{array}{c}\text { PEEP }=5 \mathrm{cmH}_{2} \mathrm{O} \\
(n=30)\end{array}$ & $\mathbf{P}$ \\
\hline Days of intubation, mean \pm SD & $9.2 \pm 8.5$ & $9.2 \pm 8.8$ & 0.79 \\
\hline \multicolumn{4}{|l|}{ Patient mortality/survival, n (\%) } \\
\hline Mortality $<28$ days & $14(42)$ & $9(30)$ & 0.39 \\
\hline Mortality $\geq 28$ days & $2(6)$ & $3(10)$ & 0.75 \\
\hline Surviving & $17(52)$ & $18(60)$ & 0.56 \\
\hline $\begin{array}{c}\text { Mortality of hypotensive } \\
\text { patients, } n / n(\%)\end{array}$ & $10 / 16(62.5)$ & 6/16 (37.5) & 0.29 \\
\hline
\end{tabular}

PEEP Positive end-expiratory pressure; ZEEP Zero end-expiratory pressure

group, 28-day mortality remained similar in both groups as was the number of intubation days (Table 4). Although $62.5 \%$ of hypotensive patients died in the ZEEP group versus $37.5 \%$ in the PEEP group (Table 4), and even if associated RRs of death appeared discriminant $(\mathrm{RR}=1.771,95 \% \mathrm{CI} 0.8387$ to 3.739 versus $R R=0.8750,95 \%$ CI 0.3646 to 2.100 , respectively), these trends were not statistically significant $(\mathrm{P}=0.2)$.

\section{DISCUSSION}

The present trial demonstrated that applying $5 \mathrm{cmH}_{2} \mathrm{O}$ PEEP instead of ZEEP during the initial 90 min postintubation ventilation setting for acute respiratory failure did not significantly change systemic hemodynamics (ie, arterial blood pressure), nor did it further alter or sustain hypotension, regardless of incurring or pre-existing conditions.

Urgent airway management is potentially problematic, and pre-existent hypotension as well as a postintubation period of hypotension is not rare (2-4). Postintubation hypotension results from a blunted sympathetic response, which, in turn, stems from resolution of hypoxia, hypercapnic, direct drug-induced negative inotropic effect, vasodilation and, occasionally, low volumic status. The consequent decrease in sympathetic vascular tone may, therefore, result in hypotension by exacerbating a decrease in cardiac preload and afterload from relative or absolute hypovolemia. In the present cohort of patients, the occurrence of hypotensive events subsequent to endotracheal intubation on the medical ICU ward was relatively similar to that reported by Mort (4) outside of the operating room. It was, however, much higher than that observed in the study by Jaber et al (2), who reported a $25 \%$ incidence on a surgical ICU ward with an anesthesia staff (2). Several reasons can explain this higher rate in our study: the observation period was longer (ie, $90 \mathrm{~min}$ ) and took into account PEEP settings; up to $30 \%$ of patients were 
already hypotensive before ETT placement; causal sepsis was highly prevalent (ie, more than 50\%); and there was no standardized procedure for anesthetic drug selection.

The use of PPV with PEEP in these 'freshly' intubated and potentially 'hypovolemic' patients undergoing general anesthesia not only further decreases ventricular preload by impeding venous return, but also potentially decreases afterload, especially in patients with systolic dysfunction (14). Indeed, because of the prevalence of comorbidities in developed Western countries that serve aging populations, the occurrence of hypotension in the early postintubation period is a daily concern, with potential outcome consequences, including patient death (3). Consequently, ICU physicians are often, if not always, reluctant to initiate minimum prophylactic PEEP measures during the initial ventilatory period because of the risk of hypotension. However, this reluctance was not outwardly evidenced in our pilot trial, even after correction for known or assessed cardiac performance or for CVP level.

Prophylactic PEEP is generally designed to prevent dependent lung area closure/atelectasis in recumbent patients, thereby improving functional residual capacity by allowing dorsal airspaces to remain open, especially in morbidly obese patients, or by counterbalancing potential air trapping/dynamic hyperinflation in severe hypoxemic-hypercapnic chronic obstructive pulmonary disease patients (15). The impact of prophylactic PEEP on partial pressure of oxygen $\left(\mathrm{PaO}_{2}\right) /$ fraction of inspired oxygen $\left(\mathrm{FiO}_{2}\right)$ ratios at bedside is not always obvious when titration is not individualized, as observed in the present trial. From a practical standpoint, the titration of an external PEEP is more often justified when a $\mathrm{PaO}_{2}$ of $60 \mathrm{mmHg}$ cannot be achieved with an $\mathrm{FiO}_{2}$ of $60 \%$ or if the estimated shunt fraction is greater than $25 \%$. Consequently, systematically adding external PEEP during initial setup of the ventilator for the mere sake of applying prophylactic PEEP or physiological PEEP is not evidence based. In any event, it should be an applied strategy at bedside, as highlighted by the Esteban et al (15) study. Possible explanations, outside of the reasons described above, are unclear because prophylactic PEEP does not reduce acute respiratory distress syndrome occurrence (16), improve shunt or deadspace in nonhypoxemic trauma patients (17), or decrease chest-tube output or transfusion requirements after openheart surgery (18). Furthermore, with up to $10 \mathrm{cmH}_{2} \mathrm{O}$ PEEP, short-term application of MV does not adversely affect hemodynamics in patients following orthotopic liver transplantation (19), and $5 \mathrm{cmH}_{2} \mathrm{O}$ PEEP has never been considered to be sufficient to induce deleterious hemodynamic consequences (20-22). Nevertheless, potential comorbidities are common among ICU patients, including occasional unknown cardiac function, hypovolemia and/or acute evolutive conditions that cannot preclude or guarantee $5 \mathrm{cmH}_{2} \mathrm{O}$ PEEP to be a fail-safe procedure in the postintubation context, although the current trial was reassuring in this regard.

\section{Study limitations}

The present single-centre study had, at the outset, a low inclusion rate. It also lacked standardized procedures for anesthesia during intubation and for interventions involving arterial blood pressure restoration that were administered post hoc for the latter but not reported for the former, although assuredly a source of potential bias for analysis. The study was not sufficiently powered to delineate definitive conclusions and cannot exclude the possibility of type II statistical error due to the relatively small cohort of patients. Also, there was no analysis to compare included versus excluded patients. Furthermore, CVP measurement as a marker of circulatory volemia was not systematically assessed per se, before inclusion; $5 \mathrm{cmH}_{2} \mathrm{O}$ PEEP was not physiologically normalized to high body mass index patients (who accounted for less than $5 \%$ of the overall study population). Finally, mechanistic explanations of primary and secondary outcomes could be more effectively assessed in a larger study - ideally multicentred - to further validate the conclusions drawn in the present study.

\section{SUMMARY}

Overall, a mixed comparable population of patients representative of a general medical ICU was not affected by the initiation of $5 \mathrm{cmH}_{2} \mathrm{O}$ PEEP versus ZEEP in the early postintubation period, as assessed by the following: delta MAP over $90 \mathrm{~min}$; level of intervention when hypotension occurred or was concurrent; and distal outcome goals such as duration of intubation and overall mortality - all of which were similar in both study groups. Therefore, implementing 'prophylactic' PEEP postintubation was demonstrated to be safe in the present small trial; however, avoiding the use of prophylactic PEEP may be detrimental, although mortality rate was not affected in the present cohort.

ACKNOWLEDGEMENTS: The authors gratefully acknowledge the invaluable help of Caroline Lambert from the Département d'Inhalothérapie (Centre Hospitalier Universitaire de Sherbrooke [CHUS]), and Nathalie Carrier (CRC-CHUS) for reviewing the manuscript and advising on statistical procedures. The authors are grateful to J Abel and E Deland for their valued and continued collaboration.

FUNDING: This work was supported by the Département de Médecine du CHUS.

\section{REFERENCES}

1. Pierson DJ, Kacmarek RM. Foundations of Respiratory Care. New-York: Churchill Livingstone, 1992.

2. Jaber S, Amraoui J, Lefrant JY, et al. Clinical practice and risk factors for imediate complications of endotracheal intubation in the intensive care unit: A prospective, multiple center study. Critical Care Med 2006;34:2355-61.

3. Schwartz DE, Matthay MA, Cohen NH. Death and other complications of emergency airway management in critically ill adults: A prospective investigation of 297 tracheal intubations. Anesthesiology 1995;82:367-76.

4. Mort TC. Unplanned tracheal extubation outside the operating room: A quality improvement audit of hemodynamic and tracheal airway complications associated with emergency tracheal reintubation. Anesth Analg 1998;86:1171-6.

5. Fulkerson WJ, MacIntyre NR, eds. Problems in Respiratory Care: Complications of Mechanical Ventilation. Philadelphia: JB Lippincott, 1991.

6. Marini JJ, Culver BH, Butler J. Mechanical effect of lung distension with positive pressure on cardiac function. Am Res Respir Dis 1981;124:382-6.

7. Van den Berg PCM, Jansen JRC, Pinsky MR. Effect of positive pressure on venous return in volume-loaded cardiac surgical patients. J Appl Physiol 2002;92:1223-31.

8. Villar J, Slutsky A. PEEP or no PEEP. Clin Pulmon Med 1996;3:279-87.

9. Luce JM. The cardiovascular effects of mechanical ventilation and positive end-expiratory pressure. JAMA 1984;252:807-11. 
10. Biondi JW, Schulman DS, Soufer R, et al. The effect of incremental positive end-expiratory pressure on right ventricular hemodynamics and ejection fraction. Anesth Analg 1988;67:144-51.

11. Kumar A, Falke KJ, Geffin B, et al. Continuous positive-pressure ventilation in acute respiratory failure. $\mathrm{N}$ Engl J Med 1970;283:1430-6.

12. Schreuder JJ, Jansen JRC, Versprille A. Hemodynamic effects of PEEP applied as a ramp in normo-, hyper-, and hypovolemia. J Appl Physiol 1985;59:1178-84.

13. Qvist J, Pontoppidan H, Wilson RS, Lowenstein E, Laver MB. Hemodynamic responses to mechanical ventilation with PEEP: The effect of hypervolemia. Anesthesiology 1975;42:45-55.

14. Fernandez-Mondejar E, Chavero MJ, Machado J. Prophylactic positive end-expiratory pressure: Are good intentions enough? Crit Care 2003; 7:191-9.

15. Esteban A, Anzueto A, Alia I, et al. How is mechanical ventilation employed in the intensive car unit? Am J Respir Crit Care Med 2000;161:1450-8.

16. Pepe PE, Hudson LD, Carrico JC. Early application of positive end-expiratory pressure in patients at risk for the adult respiratory distress syndrome. N Engl J Med 1984;311:281-6.
17. Vigil A, Clevenger F. The effects of positive end-expiratory pressure on intrapulmonary shunt and ventilatory deadspace in nonhypoxic trauma patients. J Trauma-Injury Infect \& Crit Care 1996;40:618-23.

18. Collier B, Kolff J, Devineni R, Gonzalez LS III. Prophylactic positive end-expiratory pressure and reduction of postoperative blood loss in open-heart surgery. Ann Thor Surg 2002;74:1191-4.

19. Krenn CG, Krafft P, Schaefer B, et al. Effects of PEEP on hemodynamics and indocyanine green kinetics in patients after orthotopic liver transplantation. Crit Care Med 2000;28:1760-5.

20. Williams DB, Kiernan PD, Metke MP, Marsh HM, Danielson GK. Hemodynamic response to positive end-expiratory pressure following right atrium-pulmonary artery bypass (Fontan procedure). J Thorac Cardiovasc Surg 1984;87:856-61.

21. McIntyre RW, Laws AK, Ramachandran PR. Positive expiratory pressure plateau: Improved gas exchange during mechanical ventilation. Can Anaesth Soc J 1969;16:477-86.

22. Pinsky M, Vincent JL, De Smet JM. Estimating left ventricular filling pressure during positive end-expiratory pressure in humans. Am Rev Respir Dis 1991;143:25-31. 


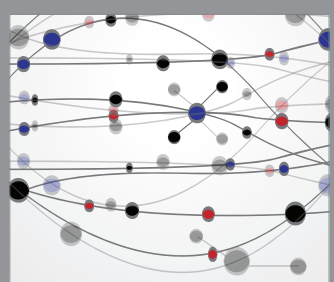

The Scientific World Journal
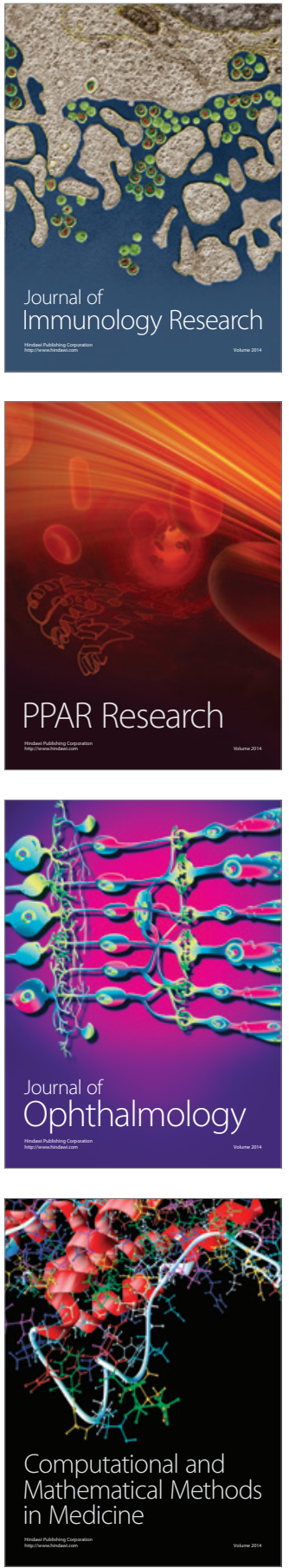

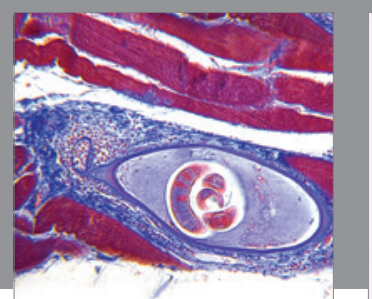

Gastroenterology Research and Practice

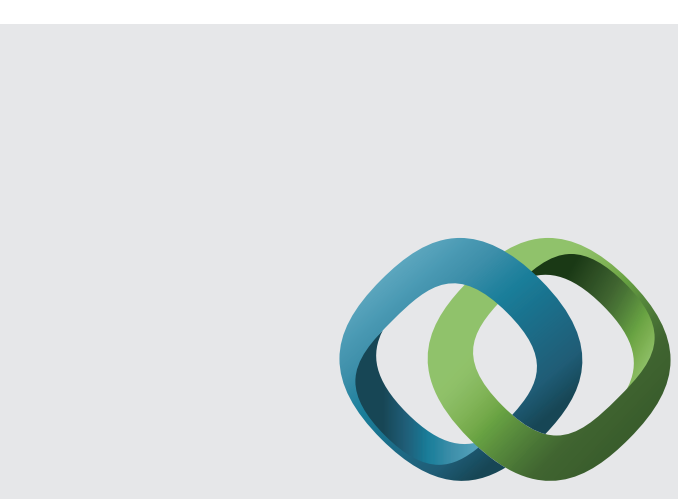

\section{Hindawi}

Submit your manuscripts at

http://www.hindawi.com
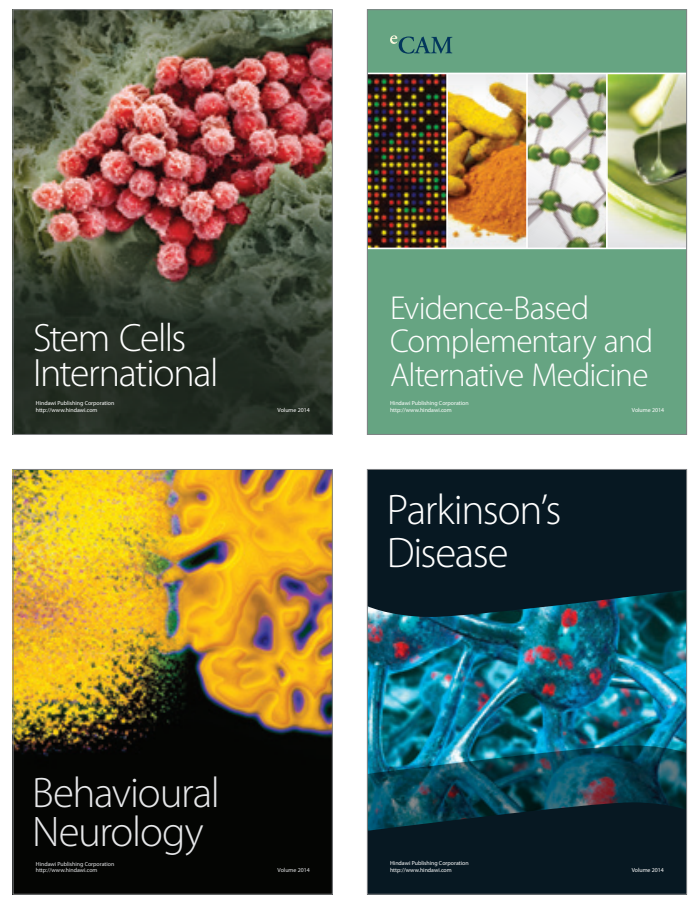
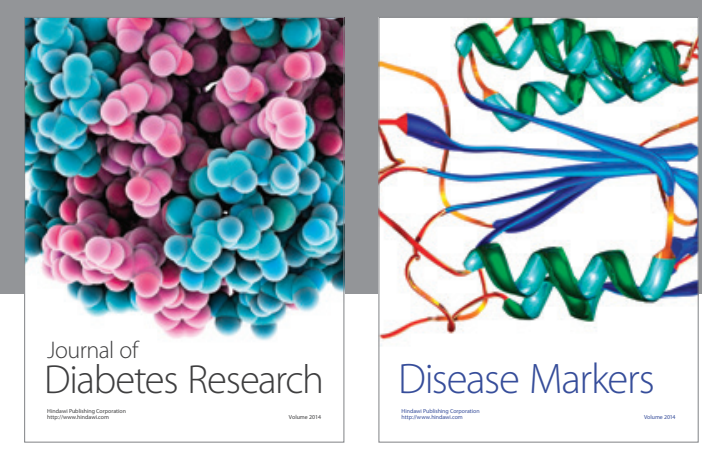

Disease Markers
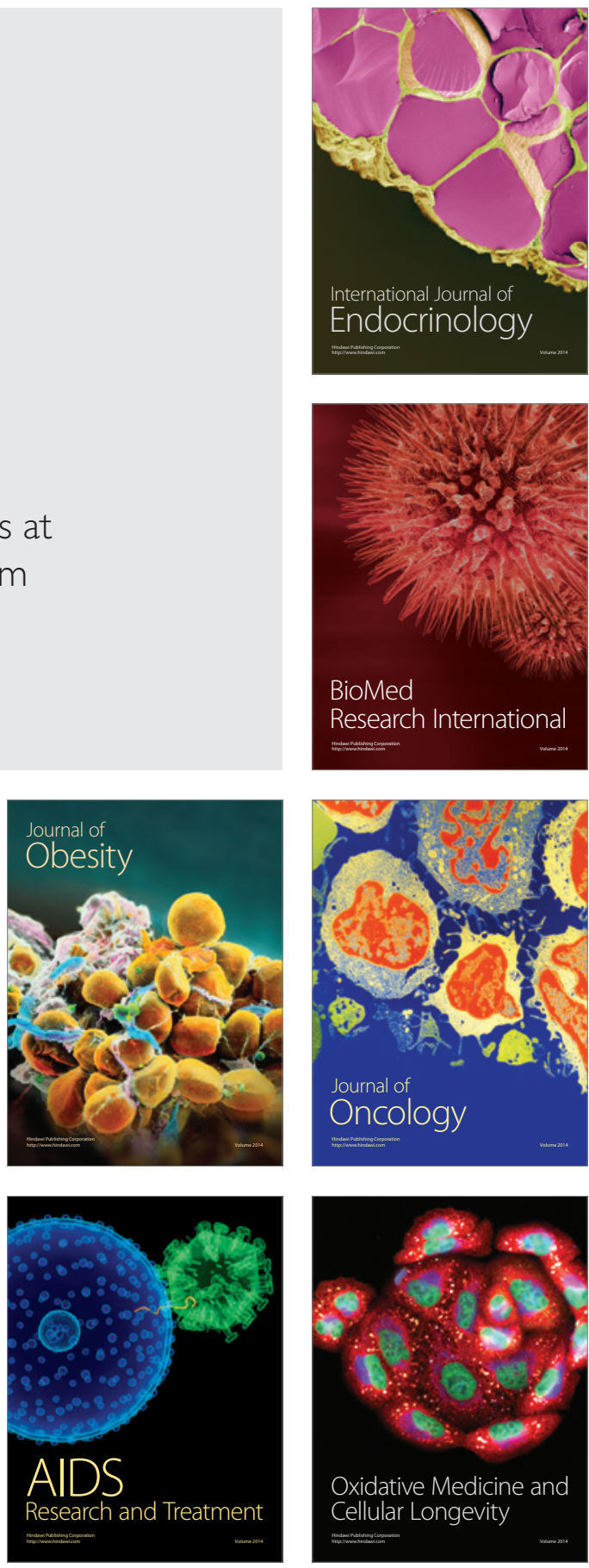